\title{
Sevoflurane induction for
}

\section{electroconvulsive therapy (ECT)- a clinical review and cost analysis}

\section{J Segal ${ }^{1,2}$, RJ Davidow}

${ }^{1}$ Tara Hospital, The H Moross Centre, Johannesburg, South Africa

2Division of Psychiatry, Faculty of Health Sciences, University of the Witwatersrand, Johannesburg, South Africa

\begin{abstract}
:
Objective: The search for an ideal induction agent for use in electroconvulsive therapy (ECT) has been a long one. To date numerous agents have been used and there is little uniformity in clinical practice regarding agent of choice. Recent reports in the literature suggesting the efficacy of the volatile anaesthetic agent sevoflurane for ECT have appeared. As a result of these reports the Tara ECT unit converted to sevoflurane for induction purposes, hence the need for both a clinical review and cost analysis. Method: This report is a retrospective clinical chart review of all patients treated with sevoflurane induction over the course of the first year of its use in this ECT unit, together with a brief cost analysis comparison to the previous induction agent used. Results: In our experience sevoflurane has been fairly well tolerated and has improved patient anaesthetic induction morbidity but appears to be associated with a shorter duration of motor seizure, potential haemodynamic complications and an increased financial burden for the hospital. Conclusion:This report is from a naturalistic setting with most patients being on concomitant medications and suffering with various medical and psychiatric problems and thus should be generalizable to other ECT units.
\end{abstract}

Keywords: Electroconvulsive therapy, ECT, Sevoflurane, Anaesthetic induction, Seizure duration, Complications.

Received: 02.12 .05

Accepted: 05.04 .06

\section{Introduction}

The induction of anaesthesia for ECT is a critical component of the treatment process as a whole. The induction agents used to date have principally been based on the opiate derivatives and as such these agents have the adverse quality of increasing the patients' seizure threshold immediately prior to administration of the electrical stimulus. The impact of this effect is to potentially shorten the duration of the induced seizure and to theoretically impact negatively on the clinical efficacy of the ECT. Commonly used induction agents include propofol, etomidate, thiopental, methohexital and ketamine. . $^{1,3}$

The impetus for developing new techniques for ECT anaesthesia induction comes from the persistent problems associated with the various agents listed above. Although a detailed analysis of these problems falls outside the scope of

\section{Correspondence:}

Dr Jose Segal, 1/12 Gardenvale Road, Caulfield, Melbourne,

Victoria,3162, Australia

email: jose.segal@easternhealth.org.au this paper they have been reviewed elsewhere. ${ }^{1,3}$ A more detailed discussion of propofol and sevoflurane will follow as these are the two agents under discussion.

\section{Propofol}

Together with thiopental, propofol is the most commonly used parenteral anaesthetic agent. ${ }^{4}$ Propofol shares qualities with other such parenteral agents including being a small hydrophobic substituted aromatic or heterocyclic compound. This class of agent is highly hydrophobic and as such it perfuses readily in to the lipophilic brain and spinal cord tissues where it produces anaesthesia within a single circulation time. Termination of anaesthesia is primarily through redistribution out of the nervous system where the agent then undergoes a complex "context-sensitive" elimination interaction between metabolism and lipopholicity. ${ }^{4}$ As propofol is essentially insoluble in aqueous solutions it is formulated as a 1\% emulsion in soybean oil, glycerol and purified egg phospholipid. ${ }^{4-6}$ Induction of anaesthesia is usually achieved using a dose of 1.5-2.5mg per Kg body mass, with unconsciousness achieved within 30 seconds, with duration of anaesthesia after a bolus dose of about 6-8 minutes. ${ }^{4,6}$ The precise mechanism of action of propofol is 
poorly understood. ${ }^{6}$ Propofol appears to have significant antiemetic effects and is a good choice for patients at risk of vomiting. Although propofol crosses the placenta it is considered safe for use in pregnancy, and it is also considered safe in patients susceptible to the development of malignant hyperthermia. ${ }^{4,5}$

\section{Problems and side effects with propofol}

Propofol has been shown to be subject to bacterial contamination and growth. As such careful aseptic technique needs to be adhered to when administering the agent. Also open vials must be used immediately and the remnants discarded without delay as the agent cannot be stored due to concerns regarding the rapid growth of microorganisms. ${ }^{5,6}$ In the United States, there is an antimicrobial agent added to the propofol preparation but this is not the case with the preparation available in South Africa. ${ }^{6}$ Intravenous administration of Propofol elicits pain on injection, which in some patients can be severe. This problem can be partially alleviated by injecting into large peripheral veins (if available) or an infusion of propofol mixed with the analgesic agent lignocain $1 \%$ (which is unfortunately also anticonvulsant) in a ratio of 20 to 1, can be used. On induction, apnoea may occur lasting longer than 60 seconds in up to $12 \%$ of patients. Cardiovascular side effects include hypotension and bradycardia. There have been reports of convulsions and involuntary movements occurring during the induction phase. Fever may also occur. Anaphylactic-like reactions have been also been reported. Nausea, vomiting, and headache have been reported during the recovery phase..$^{4-6}$

\section{Propofol and ECT}

Propofol has been a popular induction agent in many ECT centres across the globe including our unit at Tara, principally for its brief duration of action and relatively rapid recovery phase post ECT. Its use has, however, been shown to shorten seizure duration, particularly in a dose dependant fashion. ${ }^{2,1}$ Propofol induction doses in the region of 1,0$1,5 \mathrm{mg} / \mathrm{kg}$ certainly produces significantly shorter seizure duration when compared to other intravenous induction agents such as methohexital and etomidate. ${ }^{7}$ However, the impact of the propofol induced shortening of ECT seizure duration is of unknown significance. There is some data that appears to indicate that the significance, especially when treating depressive disorders is potentially limited. ${ }^{7}$ Other problems associated with propofol include the need to gain intravenous access prior to commencing the induction sequence, with the morbidity associated with this painful twice or thrice weekly procedure. Uncooperative and hostile patients may also make gaining intravenous access prior to ECT particularly problematic, commonly resulting in unacceptable escalation of tension and conflict between the patient and treating ECT team. The vascular pain associated with bolus propofol injection, which in some patients can be significant and distressing is a source of increased patient morbidity and reluctance to continue with ECT in our expreience. ${ }^{4-6}$ Propofol has been thrust into the frontline for ECT anaesthesia induction since the previous "goal standard" ECT induction agent methohexital, was removed from international distribution. ${ }^{7,8,9}$ As a result of the difficulties precipitated by methohexitals' removal other products are being investigated as alternative agents for ECT induction due to the recognition that propofol does not fully meet the needs of ECT practitioners.

\section{Sevoflurane}

Sevoflurane is a relative newcomer on the anaesthetic scene and in South Africa is marketed under the trade name Ultane $®$. Sevoflurane is a volatile anaesthetic agent ideally suited for induction of anaesthesia as it induces minimal irritation to the airways, has an easily tolerated odour and has a low blood/gas solubility. It induces rapid and smooth induction and is rapidly eliminated for ease of recovery. ${ }^{5}$ To date sevoflurane is not indicated for use in ECT specifically. ${ }^{15}$

\section{Sevoflurane and ECT}

Data relating to sevoflurane use in ECT anaesthesia induction is limited. A number of reports, albeit mixed in their conclusions, have been published showing efficacy and reasonable tolerability without excessive adverse influence on the ECT performed. ${ }^{7,11-13}$ Two of the reports showed a motor seizure duration similar to that achieved with propofol ${ }^{11,12}$, while conversely, one showed an increase duration of motor seizure when compared to propofol. ${ }^{13}$ No controlled studies have been conducted to date.

\section{Problems and side effects with Sevoflurane}

A major drawback with any gas induction in an ECT unit is the need for costly anaesthetic equipment. This equipment, including the agent specific vaporiser together with the need for a mechanism capable of delivering and mixing oxygen and/or nitrous oxide with the volatile anaesthetic agent is a prerequisite. As such, anaesthetic equipment costs are significantly increased, as is the need for increased training of the health care practitioner and nursing support staff delivering the anaesthesia. In areas remote from formal operating theatres that are typically suitably equipped, there may well be no available means of delivering volatile anaesthetic agents to a patient for ECT. Side effects commonly associated with sevoflurane use include hypotension and dose dependant depression of respiratory and cardiac function. Induction of malignant hyperthermia is also a potential problem with sevoflurane and as such it should probably be avoided if ECT is being used for the treatment of neuroleptic malignant syndrome. Nausea, vomiting, hypotension and increased coughing are the most commonly noted side effects $(>10 \%)$ in adults with elderly patients also experiencing bradycardia. Other side effects include agitation, especially in children. Laryngospasm and increased salivation may be noted. Acute renal failure has also been reported. Shivering, nausea and vomiting have been reported in the postoperative recovery period. Safety in pregnancy has not been established. ${ }^{5,15}$

\section{Induction Procedure at the Tara ECT Unit using sevoflurane}

The basic premise underlying the use of sevoflurane in our unit was to limit the patient morbidity associated with ECT. The primary aims were the avoidance of gaining intravenous access with the patient was awake, avoidance of potentially painful injection with propofol, achieving a rapid and safe induction of uncooperative patients and an effort to make the 
entire ECT induction procedure as stress free to the patient and treating ECT team as possible. In an effort to meet these needs, sevoflurane induction via facemask, using a Mc Gills circuit (bag-valve-mask) was chosen as the induction procedure of choice. After the patient has settled comfortably in bed, covered with a blanket for their comfort would the mask be placed over the patients face. The patient is dressed in their normal clothes for the day. Initially only 100\% oxygen is administered in order to allow the patient to acclimatise to the mask. After instructing the patient to breathe normally, the sevoflurane would be gradually introduced at $1-2 \%$ increments until the patient fell asleep. No effort is made to induce rapid or precipitous induction using the vital capacity rapid inhalation induction (VCRII) procedure. ${ }^{11}$ Rather a gentle and pleasant drifting off to sleep approach is aimed for.

However in cases where rapid induction is needed due to lack of patient cooperation concentrations of up to $8 \%$ sevoflurane in oxygen (up to $10 \mathrm{~L} / \mathrm{min}$ ) are given immediately. Thereafter inhaled concentrations are tapered down to maintain suitable levels of anaesthesia for the duration of the procedure. All patients would then be subjected to intravenous catheterisation, bilateral electroencephalographic (EEG) monitoring, electrocardiographic (ECG) monitoring, and continuous blood pressure, pulse and oxygen saturation monitoring. Limb isolation would be performed prior to intravenous scoline injection. Glycopyrrolate or atropine is not used routinely in our unit unless called for during a stimulus titration protocol. ${ }^{14}$ At the end of the therapeutic convulsion, all monitoring wires and electrodes are removed from the patient barring finger pulse oxymetry. Recovery is performed by dedicated recovery staff, with continuous oxygen delivery via face mask, blood pressure, pulse and pulse oxymetry monitoring. All ECT is performed with a Thymatron System IV ®TM machine, modified to deliver $1008 \mathrm{mC}$ of charge at maximum levels (200\%, $70 \mathrm{~Hz}, 1$ millisecond pulse width).

\section{Methods}

In this brief report a retrospective chart review was conducted at the end of the first year of use of sevoflurane in our ECT unit, commencing in July of 2004 to the end of June 2005. All patients referred for ECT during the study period were identified and their clinical and ECT records recovered. All relevant data was extracted from the records with every effort being made to ensure that the confidentiality of the patient concerned was maintained. Consent for the study was obtained from the Tara Hospital Ethics Committee and also from the University of the Witwatersrand Committee on Human Research. The data was subjected to basic statistical analysis.

\section{Results/Discussion}

A total of 14 patients were treated with ECT during the allocated time period, of which data was available for analysis on 13. One patient had withdrawn consent after a stimulus titration session and was not further treated with ECT and as a result was not included in the analysis.

\section{Demographic and patient data (Table I)}

Age ranged from 19 years to 73 years, with a mean of 44.23 years ( $\mathrm{SD}=19.09)$ with 11 being female [84\%] and only 2 being male [15\%]. The majority of patients (10 of 13 [76,9\%]) were referred for ECT due to multidisciplinary team (MDT) assessment of non-response to various treatment options offered, including pharmacological, psychological and milieu therapy. The severity of psychiatric illness within the group is reflected by the number of patients (6 of 13 [46\%]) who were referred for catatonic type symptoms, many of whom displayed severe life-threatening signs like refusal to eat. The DSM-IV TR ${ }^{16}$ diagnostic assessments revealed that all the patients (13 of 13 [100\%]) were suffering from psychotic symptoms at the time of referral for ECT. Schizophrenia or schizoaffective disorder as the primary diagnosis in less than a third of the group (4 of 13 [30.7\%]). The majority of patients were treated for severe mood disorders with psychotic features (8 of 13 [61\%]) with most of those being diagnosed with unipolar depressive illness (6 of 8 [75\%]). Within the mood-disordered group it was noted that a number of the patients had abnormalities on imaging studies (4 of 8 [50\%]) which were considered to play a role in contributing to the non-response to pharmacological intervention seen in these patients. Only one patient ( 1 of 13 [7\%]) was referred for ECT due to a primary diagnosis of a general medical condition (GMC) presenting with severe psychiatric symptoms.

\section{Table I: Demographic Data and Patient Details}

\begin{tabular}{|c|c|c|c|c|c|c|}
\hline Case & $\begin{array}{l}\text { Age } \\
\text { (Yrs) }\end{array}$ & Sex & Race & $\begin{array}{l}\text { DSM-IV TR } \\
\text { Diagnosis }\end{array}$ & $\begin{array}{l}\text { Medical/Comorbid } \\
\text { Diagnosis }\end{array}$ & $\begin{array}{l}\text { Reason for ECT } \\
\text { Referral }\end{array}$ \\
\hline 1 & 55 & $\mathrm{M}$ & $\mathrm{w}$ & $\begin{array}{l}\text { SAD-bipolar type } \\
\text { depressed and } \\
\text { psychotic }\end{array}$ & \begin{tabular}{|l} 
Psoriasis \\
Alcohol abuse \\
Heavy smoker
\end{tabular} & $\begin{array}{l}\begin{array}{l}\text { Treatment non- } \\
\text { response }\end{array} \\
\end{array}$ \\
\hline 2 & 19 & $\mathbf{F}$ & B & $\begin{array}{l}\text { Catatonic } \\
\text { Schizophrenia }\end{array}$ & \begin{tabular}{|l} 
Borderline \\
intellectual \\
function
\end{tabular} & Mute, not eating \\
\hline 3 & 66 & $\mathbf{F}$ & w & $\begin{array}{l}\text { MDD with } \\
\text { Psychosis }\end{array}$ & RBBB & $\begin{array}{l}\text { Treatment non- } \\
\text { response }\end{array}$ \\
\hline 4 & 23 & $\mathrm{M}$ & B & $\begin{array}{l}\text { Catatonic } \\
\text { Schizophrenia, with } \\
\text { depression. }\end{array}$ & \begin{tabular}{|l} 
Alcohol abuse \\
Chest X Ray: Old TB \\
scarring Lt Upper Lobe. \\
T-wave changes. CTB- \\
Involutional changes \\
\end{tabular} & Not eating \\
\hline 5 & 31 & $\mathbf{F}$ & B & \begin{tabular}{|l|} 
Catatonia, \\
depressed and \\
psychotic due to a GMC
\end{tabular} & $\begin{array}{l}\text { HIV, PID, HIV induced } \\
\text { dementia. CTB normal. }\end{array}$ & $\begin{array}{l}\text { Not eating, poor } \\
\text { response to } \\
\text { medication }\end{array}$ \\
\hline 6 & 52 & $\mathbf{F}$ & B & $\begin{array}{l}\text { MDD: psychotic with } \\
\text { catatonia. Alcohol } \\
\text { induced persisting } \\
\text { dementia }\end{array}$ & $\begin{array}{l}\text { Alcohol dependence } \\
\text { Serum TPHA positive } \\
\text { Urinary incontinence } \\
\text { L.P. Normal }\end{array}$ & $\begin{array}{l}\text { Treatment non- } \\
\text { response }\end{array}$ \\
\hline 7 & 32 & $\mathbf{F}$ & I & $\begin{array}{l}\text { BMD I - Mania, with } \\
\text { psychosis }\end{array}$ & $\begin{array}{l}\text { CTB-Involutional } \\
\text { changes }\end{array}$ & $\begin{array}{l}\text { Treatment non- } \\
\text { response }\end{array}$ \\
\hline 8 & 52 & $\mathbf{F}$ & w & $\begin{array}{l}\text { BMD I } \\
\text { depressed with } \\
\text { psychosis }\end{array}$ & $\begin{array}{l}\text { Hyper- } \\
\text { Cholesterolaemia }\end{array}$ & $\begin{array}{l}\text { Treatment non- } \\
\text { response }\end{array}$ \\
\hline 9 & 30 & $\mathrm{~F}$ & B & $\begin{array}{l}\text { MDD: mood } \\
\text { congruent psychosis }\end{array}$ & \begin{tabular}{|l|} 
Infertility \\
\end{tabular} & $\begin{array}{l}\begin{array}{l}\text { Treatment non- } \\
\text { Response }\end{array} \\
\end{array}$ \\
\hline 10 & 55 & F & $\mathrm{w}$ & \begin{tabular}{|c|c|} 
Continuous schizophrenia \\
\end{tabular} & Nil & $\begin{array}{l}\text { Treatment non- } \\
\text { Response }\end{array}$ \\
\hline 11 & 73 & F & w & $\begin{array}{l}\text { MDD: psychotic, } \\
\text { Catatonic excitement }\end{array}$ & $\begin{array}{l}\text { MRI-multiple deep } \\
\text { white matter infarcts } \\
\text { and corpus callosum } \\
\text { atrophy }\end{array}$ & $\begin{array}{l}\text { Treatment non- } \\
\text { Response, not } \\
\text { eating }\end{array}$ \\
\hline 12 & 67 & F & W & $\begin{array}{l}\text { MDD: mood } \\
\text { congruent psychosis }\end{array}$ & $\begin{array}{l}\text { MRI-multiple deep } \\
\text { white matter infarcts }\end{array}$ & $\begin{array}{l}\text { Treatment non- } \\
\text { Response }\end{array}$ \\
\hline 13 & 20 & $\mathbf{F}$ & B & $\begin{array}{l}\text { MDD: mood } \\
\text { congruent psychosis with } \\
\text { catatonia: post-partum } \\
\text { onset }\end{array}$ & \begin{tabular}{|l|} 
CTB: calcified \\
granuloma- Rt frontal \\
lobe
\end{tabular} & $\begin{array}{l}\text { Treatment non- } \\
\text { Response, not } \\
\text { eating. }\end{array}$ \\
\hline \multicolumn{7}{|c|}{ 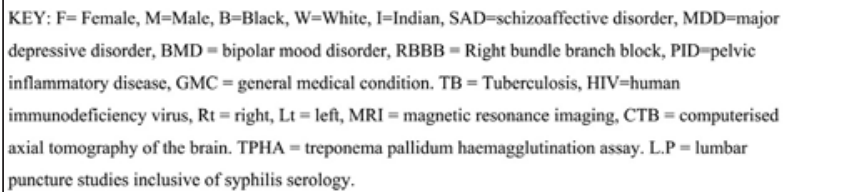 } \\
\hline
\end{tabular}

\section{ECT data (Table II)}

In total, 10 patients received high dose right unilateral (RUL) ECT of which three were subsequently converted to a bifrontal (BF) placement. Two patients received BF ECT from the outset, with only one patient receiving bitemporal (BT) ECT from the outset. Most patients $(\mathrm{N}=12$ ) had a stimulus titration protocol at their first treatment regardless of 


\begin{tabular}{|c|c|c|c|c|c|c|c|c|}
\hline Case & $\begin{array}{c}\text { Age } \\
\text { Yrs }\end{array}$ & $\begin{array}{l}\text { Thres } \\
(\mathrm{mC})\end{array}$ & \begin{tabular}{|l} 
Elect Ple \\
Initial (No)
\end{tabular} & $\begin{array}{l}\begin{array}{l}\text { Elect Ple } \\
\text { Final (No) }\end{array}\end{array}$ & $\begin{array}{l}\text { Total } \\
\text { ECT } \\
\text { (No) }\end{array}$ & $\begin{array}{l}\text { EEG } \\
\text { Duration } \\
\text { Mean (sd) }\end{array}$ & $\begin{array}{c}\text { EMG } \\
\text { Duration } \\
\text { Mean (sd) }\end{array}$ & $\begin{array}{l}\text { Meds } \\
\text { (No) }\end{array}$ \\
\hline 1 & 55 & 126 & RUL (3) & $\mathrm{N} / \mathrm{A}$ & 3 & $\begin{array}{c}45.33 \\
(18.84)\end{array}$ & $\begin{array}{r}\begin{array}{r}15.66 \\
(15.14)\end{array} \\
\end{array}$ & 8 \\
\hline 2 & 19 & 25.2 & RUL (6) & BF (1) & 7 & $\begin{array}{c}45.1 \\
(20.07)\end{array}$ & $\begin{array}{c}30.85 \\
(13.209)\end{array}$ & 3 \\
\hline 3 & 66 & $\mathrm{~N} / \mathrm{A}$ & BT (13) & $\mathrm{N} / \mathrm{A}$ & 13 & $\begin{array}{r}33.08 \\
(5.807)\end{array}$ & $\begin{array}{l}20.41 \\
(5.696)\end{array}$ & 5 \\
\hline 4 & 23 & 50.4 & RUL (4) & $\mathrm{BF}(2)$ & 6 & $\begin{array}{c}3.007) \\
(18.239)\end{array}$ & 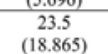 & 2 \\
\hline 5 & 31 & 126 & $\mathrm{BF}(9)$ & N/A & 9 & $\begin{array}{r}21.66 \\
(4.848) \\
\end{array}$ & $\begin{array}{c}18.14 \\
(5.988)\end{array}$ & 6 \\
\hline 6 & 52 & 151.2 & $\mathrm{BF}(11)$ & $\mathrm{N} / \mathrm{A}$ & 11 & $\begin{array}{c}24.9 \\
(12.33)\end{array}$ & $\begin{array}{c}18.4 \\
(7.734)\end{array}$ & 5 \\
\hline 7 & 32 & 151.2 & RUL (8) & N/A & 8 & $\begin{array}{c}24.25 \\
(20.755)\end{array}$ & $\begin{array}{c}14.5 \\
(7.368)\end{array}$ & 6 \\
\hline 8 & 52 & 50.4 & $\operatorname{RUL}(6)$ & $\mathrm{N} / \mathrm{A}$ & 6 & $\begin{array}{l}16.833 \\
(4.446)\end{array}$ & $\begin{array}{c}12.5 \\
(2.881)\end{array}$ & 8 \\
\hline 9 & 30 & 50.4 & RUL (1) & $\mathrm{N} / \mathrm{A}$ & 1 & $\begin{array}{l}33 \\
(0)\end{array}$ & $\begin{array}{l}33 \\
(0)\end{array}$ & 3 \\
\hline 10 & 55 & 25.2 & RUL (2) & $\mathrm{N} / \mathrm{A}$ & 2 & $\begin{array}{c}34.5 \\
(2.121)\end{array}$ & $\begin{array}{c}28 \\
(1.414)\end{array}$ & 1 \\
\hline 11 & 73 & 100.8 & RUL (7) & $\mathrm{BF}(2)$ & 9 & $\begin{array}{r}37.333 \\
(16.363)\end{array}$ & $\begin{array}{r}20.666 \\
(13.883)\end{array}$ & 4 \\
\hline 12 & 67 & 100.8 & RUL (7) & $\mathrm{N} / \mathrm{A}$ & 10 & $\begin{array}{c}29.0 \\
(5.831)\end{array}$ & $\begin{array}{r}12.40 \\
(5.211) \\
\end{array}$ & 2 \\
\hline 13 & 20 & 100.8 & RUL (5) & $\mathrm{N} / \mathrm{A}$ & 5 & $\begin{array}{c}33.2 \\
(24.652)\end{array}$ & $\begin{array}{c}23.6 \\
(14.910)\end{array}$ & 6 \\
\hline \multicolumn{9}{|c|}{$\begin{array}{l}\text { KEY: Yrs }=\text { years, Thres }=\text { threshold, } \mathrm{mC}=\text { milliCoulombs of charge, Elect }=\text { electrodes, } \mathrm{Plc}=\text { placement, } \\
\mathrm{sd}=\text { standard deviation, } \mathrm{No}=\text { number, } \mathrm{N} / \mathrm{A}=\text { not applicable, } \mathrm{RUL}=\text { Right Unilateral, } \mathrm{BT}=\text { Bitemporal, } \mathrm{BF} \\
=\text { Bifrontal, Meds }=\text { concomitant medications received during the course of ETC. }\end{array}$} \\
\hline
\end{tabular}

electrode placement. Only one of the thirteen patients who was deemed a high risk for a stimulus titration due to a right bundle branch block on ECG was treated with an aged-based dosing protocol with BT ECT. Linear regression analysis found a significant negative correlation between seizure threshold and EMG duration of motor seizure $(r=-0.6283, p=0.0287)$, but not to duration of EEG seizure length ( $r=-0.2888$, $p=0.3627$ ). This finding is probably indicative of the unusually short motor seizures (but not EEG seizures) noted in this group of patients. Seizure threshold was found to correlated positively with total number of ECT's given, however failed to reach statistical significance $(r=0.5492, p=0.0644)$ and would probably have done so had there been a larger sample size. Surprisingly there was no significant correlation found between threshold and age in this group of patients $(r=0.2024$, $\mathrm{p}=0.5281)$. These data are not consistent with the ECT literature and is probably related to the small sample size. ${ }^{17,18}$

\section{ECT means data for the entire group (Table III)}

The mean seizure threshold was found to be $88.2 \mathrm{mC}(\mathrm{N}=12$, $\mathrm{SD}=46.2$ ). Data extracted for the right unilateral (RUL) ECT group revealed a threshold of $78.12 \mathrm{mC}(\mathrm{N}=10, \mathrm{SD}=43.567)$, with the threshold for females being $75.6 \mathrm{mC}(\mathrm{N}=8$, $\mathrm{SD}=4.675)$, and for the males being $88.2 \mathrm{mC}(\mathrm{N}=2$, $\mathrm{SD}=53.44)$. These results compared favourably with some previously published data. Reported means range from $61.11 \mathrm{mC}$ for the RUL group, with females at $45.04 \mathrm{mC}$ and males at $68.50 \mathrm{mC}$ in the Coffey study, to $74.8 \mathrm{mC}$ for the right unilateral group in the Beale study. ${ }^{17,14}$

Table III: Electroconvulsive Therapy (ECT) Group Means (N=13)

\begin{tabular}{|c|c|c|c|c|c|c|}
\hline & $\begin{array}{l}\text { Age } \\
\text { (Yrs) }\end{array}$ & $\begin{array}{c}\text { Threshold } \\
\text { (mC) }\end{array}$ & $\begin{array}{c}\text { Total ECT } \\
\text { (No) }\end{array}$ & $\begin{array}{l}\text { EEG } \\
\text { Duration } \\
\text { (seconds) }\end{array}$ & $\begin{array}{l}\text { EMG } \\
\text { Duration } \\
\text { (seconds) }\end{array}$ & $\begin{array}{l}\text { Meds } \\
\text { (No) }\end{array}$ \\
\hline Mean & 44.23 & 88.2 & 6.76 & 30.54 & 19.18 & 4.53 \\
\hline Sd & 19.09 & 46.21 & 3.345 & 15.087 & 10.841 & 2.259 \\
\hline Total & $\mathrm{N} / \mathrm{A}$ & $\mathrm{N}=12$ & 88 & $\mathrm{~N} / \mathrm{A}$ & N/A & $\mathrm{N} / \mathrm{A}$ \\
\hline \multicolumn{7}{|c|}{$\begin{array}{l}\text { KEY: } \mathrm{Yrs}=\text { years, } \mathrm{mC}=\text { milliCoulombs of charge, } \mathrm{No}=\text { number, } \mathrm{N} / \mathrm{A}=\text { not applicable, Meds }= \\
\text { concomitant medications received during the course of ETC. }\end{array}$} \\
\hline
\end{tabular}

For those under 40 years of age the mean threshold was found to be $84 \mathrm{mC}(\mathrm{N}=6, \mathrm{SD}=49.55)$. For those over 40 years of age the mean threshold was found to be $92.4 \mathrm{mC}$, $(\mathrm{N}=6, \mathrm{SD}$ = 46.92). Comparison between the two groups failed to reach statistical significance contrary to what one would have expected based on the published data $(\mathrm{p}=0.769, \mathrm{t}=0.30 \mathrm{l}$, $\mathrm{df}=9) .{ }^{14,17,18}$ The reasons for this is likely to be the small sample size and the numerous confounding variables in the group including the large number of concomitant medication used and the number of patients with cerebral pathology on imaging studies. As can be seen from Table I, all patients were on concomitant medications during the course of ECT.

The mean number of medications used for each patient was $4.53(\mathrm{~N}=13, \mathrm{SD}=2.259)$. The impact that these medications had on the individual seizure threshold is unclear. Analysis revealed that the majority of patients (8 of 13 [61\%]) were on threshold elevating agents like anticonvulsant and/or benzodiazepine treatments during their titration. The threshold values for this group revealed a mean of $93.6 \mathrm{mC}(\mathrm{N}=7, \mathrm{SD}=42.94)$, compared to the group treated without threshold elevating agents of $80,64 \mathrm{mC}(\mathrm{N}=5$, $\mathrm{SD}=54.63)$. Although the threshold was indeed higher in the group receiving anticonvulsant and/or benzodiazepines, analysis showed that the difference failed to reach statistical significance $(p=0.671, t=0.441, d f=7)$.

Further analysis revealed that there was no significant difference between the groups in terms of their age, EEG duration, EMG duration or total number of ECT's needed $(p=0.518, t=0.73, d f=3)$. Also linear regression analysis failed to demonstrate a significant correlation between seizure threshold and number of concomitant medications ( $r=0.5262, p=0.0788)$. It is possible that failure to show significance was a result of the small sample size. These findings may imply, however, that the influence that the anticonvulsant and/or benzodiazepine medications exerted on threshold was minimal, which is unlikely. This conclusion is supported by the finding that the mean threshold for the anticonvulsant and/or benzodiazepine group of 93.6mC ( $\mathrm{N}=7, \mathrm{SD}=42.94)$ was in comparison to the Coffey study, (threshold 61.1 l mC, SD=29.99, N=111) significantly higher ( $t=2.707, p=0.0078$, df 116$).{ }^{17}$ An alternative possibility is that the threshold for the entire sample ( $\mathrm{N}=12$ ) was artificially elevated by the sevoflurane to a point where the relative differences made by the anticonvulsants and/or benzodiazepines was lost. However, a comparison between the group without anticonvulsant and/or benzodiazepine medication with the Coffey study failed to reach significance $(t=0.794, p=0.471$, $\mathrm{df}=4) \cdot{ }^{17}$ This implies that the threshold was indeed elevated for the anticonvulsant and/or benzodiazepine group and that this resulted in the elevation of the group mean values as a whole, and thus not consistent with a sevoflurane influence.

When compared to previously published data the mean duration of motor seizure in our group of 19.18 seconds $(\mathrm{SD}=10.841)$ differed significantly, with shorter motor seizures than the sevoflurane group of Toprak et al, where the mean motor duration was found to be 43.09 seconds ( $S D=16.6$ ), resulting in a mean difference of 23.91 seconds $(p=0.001$, $\mathrm{t}=4.469, \mathrm{df}=27) \cdot{ }^{13}$ Indeed our group compared just as poorly with the propofol comparison group used in Toprak's study, which had a mean duration of motor seizure of 28.91 seconds $(\mathrm{SD}=7.9)$, with a mean difference of 9.73 seconds $(\mathrm{p}=0.094$, $\mathrm{t}=2.795, \mathrm{df}=27$ ). As pointed out by Toprak in his paper, the 
mean duration of seizures in his group were notably longer than that of the findings of other authors researching sevoflurane induction for ECT and was accounted for by the method of induction and maintenance of anaesthesia used ${ }^{11,12}$ Unfortunately, in the Toprak study no standard deviation was provided for the mean age given (27.1yrs) rendering comparative analysis impossible. ${ }^{13}$ However, it does appear that our mean age of 44.23 years was considerably higher and similar to that in the Wajima (57 years) and Calarge (40years) studies.11,12 Duration of motor seizure in the Wajima report for their sevoflurane group was 16 seconds, range (0-60s), but unfortunately mean and standard deviation values were not provided making analysis impossible. However, 16 seconds certainly approximates far more closely our findings (mean of 19.18 seconds, $s d=10.841$ ) than that of the Toprak study. ${ }^{13}$

When comparing our data with data in older populations from other studies it appears that the age variable was not a factor as our motor durations were significantly shorter than those found by both Sakeim (mean difference 26.9, $p=0.001$, $\mathrm{t}=6.775, \mathrm{df}=31$ ) and Petrides (mean difference 39.9, $\mathrm{p}=0.007, \mathrm{t}=3.955, \mathrm{df}=2 \mathrm{l}$ ) albeit using different induction agents, viz sevoflurane versus methohexital in the other two ${ }^{18,19}$ The mean ages between the three groups were not significant $(p=0.317)$.

In order to try and explain the short duration of motor seizures found in our study, one should note that these patients were treated in a naturalistic setting without any exclusion criteria, and were also on significant amounts of concomitant medications as indicated previously. The mean seizure duration in this study is certainly short, and would be considered by many to perhaps indicate that the ECT was not as effective as it should have been. However, the mean number of ECT's given in the group (6.76, sd=3.345) certainly falls within acceptable limits. Given the profound severity of psychiatric illness in the group as a whole it is perhaps surprising that more ECT's were not used. It is becoming increasingly recognised that seizure duration is not positively correlated with ECT's therapeutic efficacy and as such this naturalistic data could be said to be in support of this finding ${ }^{20}$ It is not possible, given the small number of cases, the numerous confounding variable present and the absence of an active comparator agent, to comment on the role that sevoflurane played in contributing to the short motor seizures. Other authors have been of the opinion that sevoflurane is indeed responsible for shorter duration seizures ${ }^{11,12}$ As indicated above the significance of the shorter seizure duration remains a vexing issue. If our population group is anything to go by, then it appears that the shorter duration of motor seizures is not linked to the clinical outcome in our group.

The majority of patients had a favourable outcome (Table IV) for the ECT with most of them achieving a euthymic and apsychotic state by the end of their course (8 of 13 [61\%]). In all the patients with catatonic type symptoms the catatonia resolved. However, many were left with non-responsive residual symptoms on discharge (3 of 6 [50\%]).

The majority of the side effects facing the team were cardiovascular in nature as indicated in the table. Also of significance is the rapidity and extent of threshold elevation occurring during the course of the ECT. In 9 cases ( 9 of 13 [69\%]) maximum percent energy (200\%) on our modified Thymatron System IV ®TM machine was needed to induce

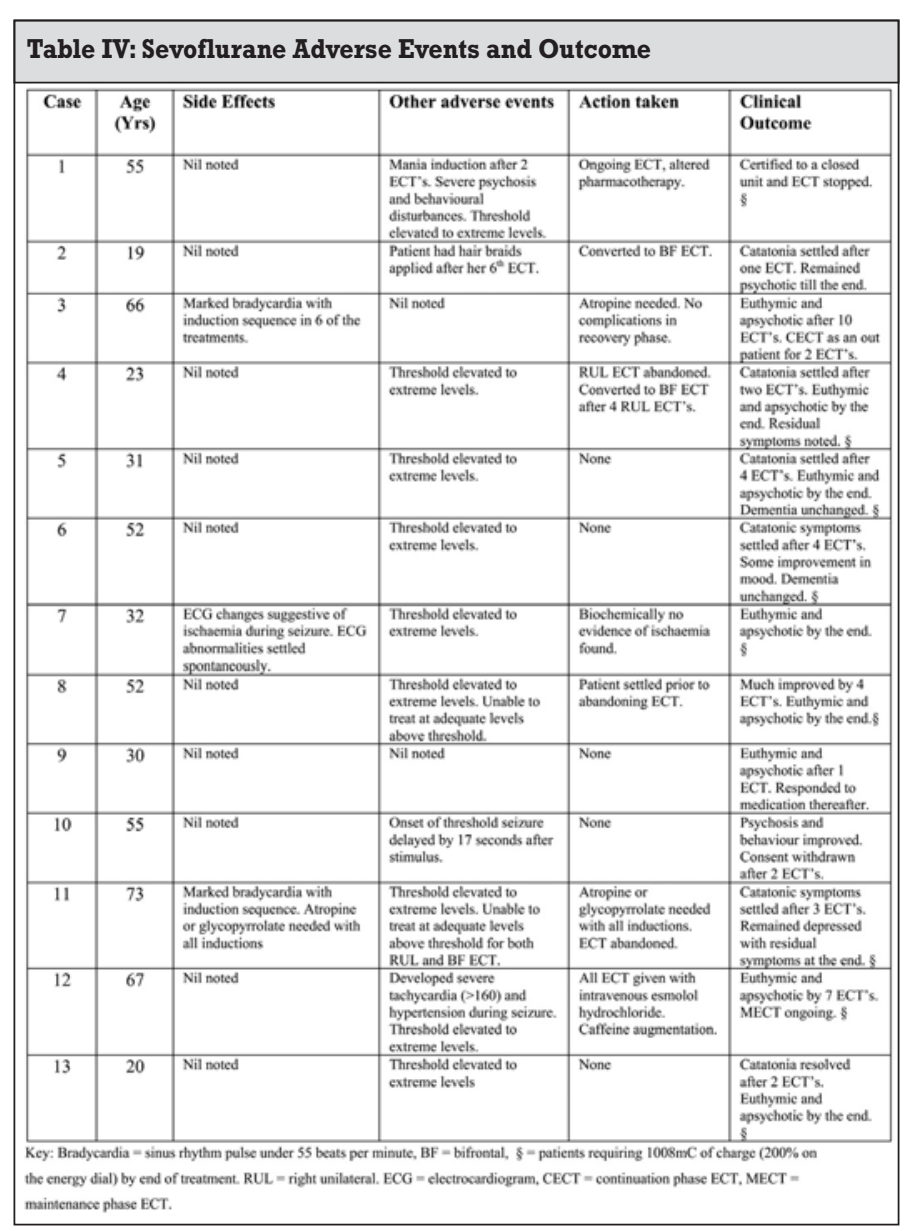

seizures of adequate duration by the end of their RUL ECT course. In two cases (4 and 1 1) RUL ECT had to be abandoned due to the dramatic rise in threshold. In case 4 , threshold on bifrontal titration was found to be $50 \%(252 \mathrm{mC})$. In case 11 threshold on bifrontal titration was found to be $150 \%$ (756mC). As discussed above, the motor seizure duration for the entire group was found to be only 19.18 seconds ( $\mathrm{sd}=10.841$ ) despite the high levels of energy used in the majority of the patients.

None of the other studies using sevoflurane has mentioned such a finding relating to seizure threshold.11-13 Caution is advised when interpreting this data due to the multiple confounding variables as outlined previously. However, in all of these patients RUL ECT would have been impossible using unmodified, standard ECT machines. It would be advisable that future studies using sevoflurane as an induction agent for ECT should be alert to the possibility of this outcome.

\section{Sevoflurane Induction; calculating the costs}

Over the period of review 12 bottles of sevoflurane 250mls had been used. Total sevoflurane costs amounted to R21773.16 over the course of the year under review. During this time a total of 16 stimulus titrations were performed (some patients were titrated more than once due to changes from RUL ECT to BF ECT), and a total of 88 successful ECT treatments were administered. If one includes all the missed treatments over the period in review the total number of stimulations was 110. One could then calculate that each ECT session's Sevoflurane use (titrations plus treatments, and stimulations that resulted in missed seizures) cost, very roughly, R173. In comparison, propofol costs R57.83 per 50ml ampoule, 
and contains a total of 500mg of propofol. This is usually sufficient in our unit for about 3 anaesthesia inductions. As a result the same number of ECT treatments using propofol as an induction agent would have cost roughly R2428.86 in total, giving a cost of just over R19 per ECT session. This means that sevoflurane is almost 9 times more expensive to use than propofol in our ECT unit. Given our current financial climate this cost analysis is of importance and should be borne in mind if other ECT units are considering using sevoflurane as an induction agent. One way of curtailing the amount of sevoflurane is to convert the McGills open circuit (bagvalve-mask) that is currently used in our unit into a closed rebreathing type with a carbon dioxide absorption system installed. However, the initial set up costs of this type of equipment is considerable and would have to be specially budgeted for by the hospital concerned. Also staff training and maintenance costs would rise considerably. Other options include initiating induction with sevoflurane and after the patient is asleep to gain intravenous access and immediately administer some propofol to maintain anaesthesia for the few minutes needed to prepare the patient and administer the ECT treatment but stop the sevoflurane as soon as the propofol has been given. The quantity of sevoflurane used may be significantly curtailed in this manner. However, untoward effects on seizure duration has been found when this approach is used. ${ }^{11}$

\section{Conclusion}

The role of sevoflurane in ECT anaesthesia remains unclear. Some data seems to suggest that it is associated with shorter duration of motor seizures, although the clinical significance of this remains elusive. It is a reasonably well tolerated agent with manageable side effects in our experience. One should remain cautious and on the alert for the depressant effects sevoflurane has on cardiac function, like pulse and blood pressure, in particular in the elderly. It is certainly preferred by our patients over intravenous induction due to the minimisation of associated morbidity. The induction and maintenance of anaesthesia technique used appears to play a role in the influence sevoflurane has on seizure duration. The technique will require refinement in order to minimise this problem. Also the potential role of sevoflurane in the elevation of seizure threshold should be systematically examined. In countries where cost analysis influences service delivery, sevoflurane will probably be found to be prohibitively expensive. Given the findings of this one year review it is not recommended that sevoflurane remain in routine use as an ECT induction agent in our unit at this time. Its use should be reserved for patients that are uncooperative or hostile during induction. It could also be considered for those patients with inaccessible peripheral veins, who are markedly averse to recurrent venepuncture or who experience intolerable venous pain with propofol injection. Further controlled research will be needed before the role of sevoflurane, if any, in the future of ECT can be firmly established.

\section{References}

1. Ding Z, White PF. Anaesthesia for electroconvulsive therapy. Anesth Analg 2002; 94: 1351-1364.

2. Avramov MN, Husain MM, White PF. The comparative effects of methohexital, propofol and etomidate for electroconvulsive therapy. Anesth Analg 1995; 81: 596-602.

3. Folk JW, Kellner CH, Beale MD et al. Anaesthesia for electroconvulsive therapy: a review. J ECT 2000; 16: 157-170.

4. Goodman and Gilman's The Pharmacological Basis of Therapeutics. Tenth Edition. International Edition. Editors Joel $G$ Hardman, Lee E Limbird. Mc Graw - Hill Medical Publishing Division, New York, 2001.

5. Martindale. The Complete Drug Reference 33rd edition, Edited by Sean C Sweetman, London, Chicago, Pharmaceutical Press The Bath Press, 2002; 1265-1267.

6. Fresenius Kabi. Propofol $1 \%$ Fresenius. Package Insert, 16 October 1998, Fresenius kabi.

7. Zhengnian D, white PF. Anaesthesia for Electroconvulsive Therapy. Anesth Analg 2002; 94: 1351-1364.

8. Kellner CH. Towards the Modal ECT Treatment (Editorial). J ECT 2001; 17: 1-2.

9. Russel E. Running an ECT Department. Advances in Psychiatric Treatment 2001; 7: 57-64

10. Smith I, Nathanson M, White PF. Sevoflurane: A long-awaited volatile anaesthetic. Br J Anaesth 1996; 76: 435-445.

11. Wajima Z, Shiga T, Yoshikawa T, et al. Propofol alone, sevoflurane alone, and combined propofol-sevoflurane anaesthesia in electroconvulsive therapy. Anaesth Intensive Care 2003; 31: 396-400

12. Calarge CA, Crowe RR, Gergis SD et al. The comparative effects of sevoflurane and methohexital for electroconvulsive therapy. J ECT 2003; 19: 221-225.

13. Toprak HI, Gedik E, Begeç Z et al. Sevoflurane as an alternative anaesthetic for electroconvulsive therapy. J ECT 2005; 21: 108-1 10.

14. Beale MD, Kellner CH, Pritchett JT, Bernstein HJ et al. Stimulus Does Titration in ECT: A 2-year clinical experience. Convulsive Therapy 1994; 10: 171-176.

15. Ultane Liquid Package Insert. Abott Laboratories South Africa (PTY) Ltd, Constantia Kloof, 3 July 2003.

16. American Psychiatric Association: Diagnostic and Statistical Manual of Mental Disorders Fourth Edition - Text Revision. Washington, DC, American Psychiatric Association, 2000.

17. Coffey CE, Lucke J, Weiner RD et al. Seizure Threshold in Electroconvulsive Therapy: Initial seizure threshold. Biol psychiatry 1995; 37: 713-720.

18. Sackeim H, Decina P, Prohovnik I at al. Seizure Threshold in Electroconvulsive Therapy: Effects of sex, age, electrode placement and number of treatments. Arch Gen psychiatry 1987; 44: 355-360.

19. Petrides G, Fink M. The Half-Age Stimulation Strategy for ECT Dosing. Convulsive Therapy 1996; 12: 138-146.

20. Fear CF, Littlejohn CS, Rouse E, et al. Propofol Anaesthesia in Electroconvulsive Therapy. Reduced seizure duration may not be relevant. Br J Psychiatry 1994; 165: 506-509. 